\title{
规范学校学生管理 加强学生自主管理
}

梅燕飞

云南经济管理学院

DOI:10.32629/er.v1i5.1557

[摘 要] 大学生管理是高校管理的主要内容, 受高校学生管理队伍人员数量和质量的制约,随着社会的不断发展, 传统的高校 教育理念及教育模式已经不能满足当代学生的发展,因此,要随着形式的变化加强对学生的管理。自主管理模式的形成,要求学 生树立基本的自主管理理念高校要以人为本, 提高学生的自主性,进而形成科学的自主管理体系。本文就加强学生自主管理的 内涵、必要性、原则和培养出人才的素质等几个方面进行论述。

[关键词] 规范; 学生管理; 自主

\section{1 加强学生自主管理的内涵}

现代企业管理最早提出自主管理这个概念, 企业员工通 过有效管理和维护现场、设备以及工程, 让设备和现场管理 始终保持理想状态。学生自主管理模式是在教师的引导和鼓 励下, 学生自主对自身的日常学习和社会生活进行管理。与 企业自主管理相同的是, 学生自主管理也必须具备以下三个 要素:

(1) 学生需要具备一定的自主管理意识, 要让学生认为 他们自身就可以实现学校对学生的管理工作, 从而积极地参 与到具体的管理工作中。

(2) 学生需要具备相应的自主管理能力, 只有具备了一 定的管理能力和管理方法才能顺利开展自主管理工作。

(3) 学生在参与具体的自主管理工作中, 需要将自身的 想法落到实处, 用实践实现自主管理。三者相辅相成, 互相促 进, 学生应该主动参与自身密切相关的管理工作。究其本质, 学生自主管理方法不仅是管理方法和管理机制, 还是未来高 校管理工作的发展方向。

\section{2 高校大学生自主管理的必要性}

2.1 培养学生自主管理能力, 实现高校持续发展

如今, 高等教育普遍开来, 每年的学生人数也在不断地 递增, 致使学校的管理工作没能及时完善, 高校应该加强对 大学生的管理工作。同时, 学生对学校的管理出现了很多不 满的地方, 不是去采取合理、有效的方法解决, 而是消极的态 度去对待, 导致这种情况的形成, 很大程度上由于学校管理 工作不到位。为了满足社会对高素质人才的需求, 学生的全 面发展, 高校大学生的自主管理创新工作显得非常重要。高 校在以学生为本的前提下, 积极培养大学生的自主能力和自 律意识, 实现高校的持续发展。

2.2 学生自身能力的提高, 自主管理是一个重要渠道

社会的竞争, 不仅是知识的竞争, 更是素质与能力的竞 争, 学习成绩的好坏并不代表能力的强弱。在大学的学习期 间, 课业任务并不繁重, 这为学生们提升自身能力提供了很 大空间。步入社会, 学校的专业知识用到的并不多, 更多的是 面对不同环境的学习能力和随机应变能力。大学就好比一个
加工厂, 输出的就是人才, 在新的社会形势下, 高校的主要任 务就是为学生提供帮助, 培养有能力、有素质的新型人才。 因此, 在学生的学习时期, 学校除了提升学生的知识储备, 还 要为学生提供更多的平台, 让学生充分发挥自身才能, 提高 学生独立创新能力、社会适应能力。而这些能力的提高, 自 主管理是一个有效的重要渠道。

\section{3 加强学生自主管理所遵循的原则}

3.1 主体性原则

在教学过程中, 尊重学生的主体地位, 发挥学生的主体 性, 是学校进行学生自主管理的一个重要原则。贯彻落实主 体性原则, 主要体现在以下几个方面: 首先, 要确立教师的主 导作用, 但并非是主宰作用, 教师应该主动培养学生的主体 地位, 教会学生学习和做人做事。其次, 调动学生的积极性, 让学生能够有足够的激情和充沛的精力投身到学习和实践 中, 才能够真正体现学生自主管理的优势。最后, 给学生足够 的自由活动的时间和空间。让学生有更充裕的时间来进行自 学、思考、交流、讨论、反思, 使学生真正学会学习, 增强学 生的使命感和责任感。

\section{2 民主性原则}

“民主性原则是指在教育教学过程中, 师生处于平等地 位, 师生在活动中教学相长, 师生的关系是一种平等和谐的 人际关系。” 贯彻落实民主性原则, 主要表现在: 首先, 尊重 学生独立人格。这也是教学的基本要求, 只有教师对学生给 予基本的尊重, 才能保证教学活动的顺利进行, 教师歧视学 生会对学生的身心造成巨大伤害, 影响学生人格的发展。其 次, 师生地位的平等。教师并没有高学生一等, 学生也没有矮 教师一截, 两者是平等的个体。在教学过程中, 应该形成互尊 互爱、平等民主、和谐有爱的师生关系。最后, 教师要对所 有学生一视同仁。教师在教学活动中不能因为学生的家庭背 景、个人习惯等对学生产生偏见。要公平对待每一个学生, 确保每一个学生都获得平等的教学机会。

\section{3 活动性原则}

在学生进行自主管理的过程中, 要把活动贯穿其中。能 够最大限度地调动学生的创造性、主体性, 使学生在办活动 
的过程中, 不断总结自我、反思自我, 让学生受教育的过程成 为自我学习、自我管理的实践过程。

3.4 贯彻落实活动性的原则

首先, 活动要有针对性, 活动的内容和目标要根据学生 的实际情况和当前的思想状况确立。不能够脱离学生的实际 情况, 靠空想进行决策。例如可以开展创业竞赛, 但是绝对不 可以要求学生在一个月内赚 100 万。其次, 活动具有自主性, 活动虽然由教师主导, 但是具体的内容, 比如说活动的形式、 活动的内容、活动的规模, 应该由学生讨论确定。教师从旁 协助。最后, 活动有效性。学校组织活动是为了引导学生的 创新思维, 提高学生的组织能力和领导能力, 因此学校在举 办活动的过程中, 应该有侧重地培养学生这方面的能力, 不 能让活动没有任何意义, 真正做到每一场活动都有成效。

\section{5 开放性原则}

学校绝对不能以一个封闭的个体存在, 这就要求在教学 活动中与社会紧密联系, 发现社会需求, 培养学生相应的能 力, 为社会培养出有市场的人才, 在教育和实践活动中, 激发 学生的活力、创造力和创新能力, 重视学生个性化的培养, 鼓励学生参加社会活动, 增加工作经验, 把握社会变化, 把社 会发展与自身发展紧密联系, 在这种开放式的锻炼中找准自 己的爱好所在, 坚定自己的发展方向, 并不断地为了自己的 梦想拼搏, 实现长久发展。

\section{4 大学生自主管理的实践初探}

4.1 注重培育学生的 “独立自主” 意识, 增强学生的综 合能力

首先, 明确大学生应具备的综合能力。学生的个性会在 自我管理中得到充分发展, 通过参与自主管理, 学生有足够 的时间完善自我、创造自我, 其组织能力、创造能力、竞争 能力、生存能力、沟通能力、以及实践能力都能够得到充分 锻炼和培养。

其次, 管理者应合理地引导学生培育自身独立自主意识, 增强自身的综合能力。引导学生主动参与到学生管理工作中, 同时培养学生的管理能力、实践能力和创新精神。管理者的 职责是为学生服务, 在服务中对学生进行教育, 将教育蕴含 在服务之中。为了给学生提供更加宽松的学习环境和沟通环 境, 教师应在大方向上对学生进行充分指导, 让学生的主观 能动性得以充分发挥, 在管理过程中监督、调整以及总结; 在管理学校事务过程中, 学校应给予学生一定的发言权, 让 学生更加关注自身的权益。

4.2 发挥学生骨干及学生组织的作用, 提升学生的自治
能力

首先, 必须充分发挥学生骨干和学生组织的服务作用。 所以, 对于学生会、学生党支部和班委会, 学校应给予他们一 定的权利, 引导其它学生进行自我管理、自我教育。正如前 苏联教育专家苏霍姆林斯基曾经说过: “根据我的经验, 能够 唤起人进行自我教育的教育才是真正的教育。”故而, 依靠学 生骨干及学生组织实现学生的自治亦尤为重要。

其次, 鼓励学生定期组织相关活动, 密切关注学生的发 展动向。可以举行体育竞赛、书法比赛、英语竞赛、演讲比 赛以及数学建模等活动, 让不同的学生发挥自身的优势, 并 在此基础上宣传自我服务的精神。为了能够及时了解学生的 心理状况, 学院可以在每个班级安排一名心理委员, 将问题 消灭在萌芽状态。相对来说, 学生骨干在学生群体中是比较 优秀的, 他们与其他学生关系密切, 更加了解周围同学的发 展动向, 在帮助工作人员引导学生发展以及更好地服务学生 等方面都是不可或缺的。

\section{3 注重学生工作, 加强辅导员队伍建设}

构建学生队伍的建设, 加强对大学生工作的重视, 高校 教职员工承担起自身责任, 同时, 高校还应增强辅导员队伍 的创设, 在我国多数高校中, 辅导员一直从事学生管理的工 作, 加强辅导员队伍的创设, 在学生自主管理工作中, 起着推 动作用。高校应该加强对辅导员队伍的训练, 重视提高辅导 员自身素养, 提升其管理水准, 更好地为学生的自主管理服 务。

\section{5 结语}

大学生这个群体比中小学生更主动, 具有较高的参与性 和自主意识。树立学生自主管理观念, 让学生主动参与学校 的日常管理工作, 十分符合大学生群体的基本特征。所以, 在高校大学生管理中, 应当充分融入自主管理理念, 促进高 校学生管理水平的提升, 促进校园的稳定, 保证教育事业各 项工作的顺利开展。

\section{[参考文献]}

[1]康小强.创建自主管理社区:民办高校学生公寓管理 初探[D].华中师范大学.2015,(02):53.

[2]徐洪霞.大学生自主管理和创新能力的培养[J].课程 教育研究,2014,(12):15.

[3] 赵宁.加强民办高校学生管理法制化对策讨论[J].新 西部,2015,(30):57.

[4]李艳.科学把握对民办高校学生的管理策略[J].现代 交际,2014,(03):47+49. 